\title{
The status of the Fuerteventura Stonechat Saxicola dacotiae: a new evaluation using distance sampling and GIS
}

\author{
EDUARDO GARCIA-DEL-REY
}

\begin{abstract}
Summary
The status of the 'Endangered' Fuerteventura Stonechat Saxicola dacotiae, a western Palearctic single island endemic, was assessed 22 years after the first population estimate of 1,300-1,700 individuals was made by Bibby and Hill (1987). Using GIS and Distance Sampling methodologies, the population on Fuerteventura in 2008 was estimated at 1,035 birds $(832-1,287)$ with the species more abundant on hillsides than in gullies. Within the island's three main massifs (i.e. north, west and south) the highest encounter rate was recorded in the northern massif. This study supports the category of 'Endangered' for this species, which does face the obvious threat from development, particularly in the south of the island. The species is also on the endangered list nationally (Spain) and in Europe but has not as yet been evaluated by the Canarian Government. I suggest, based on results of this study, that serious effort should be put in to improving knowledge of the distribution range of this endemic (either by modelling or by systematic visits to sites). An official monitoring programme should be developed and implemented with special attention paid to the three main mountain ranges of this island and particularly to the southern massif which is suffering the highest rate of habitat loss.
\end{abstract}

\section{Introduction}

The Canary Islands, lying off the coast of Morocco, are of volcanic origin and have never been joined to the African continent (Fernandez-Palacios and Martin-Esquivel 2001). This isolation has contributed to high levels of endemism within its avifauna (Garcia-del-Rey 2001, Izquierdo et al. 2004). The archipelago of seven main islands and four smaller islands belong to the biogeographical region of the Atlantic islands (also named Macaronesia) and are considered as a high priority biodiversity area in Europe (Stattersfield et al. 1998, Tucker and Evans 1997).

Of the five full endemic bird species in the Canaries, the Fuerteventura Stonechat Saxicola dacotiae (Meade-Waldo 1889) has the smallest range of all. Two subspecies have been described S. dacotiae dacotiae occurs on Fuerteventura and $S$. $d$. murielae which is already extinct on Alegranza and Montaña Clara (off Northern Lanzarote) (Bannerman 1913). Species status of the Fuerteventura Stonechat has been supported genetically (Wink et al. 2002) making it one of the scarcest species to breed within the western Palearctic and one of a tiny number of single island endemics to occur in the region.

Fuerteventura $\left(1,655 \mathrm{~km}^{2}\right)$ is the second largest island in the archipelago and, at 20 million years old, the oldest of all the Canary Islands. Much of the island is a flat semi-desert with coastal scrub dominating the landscape, but with three mountain ranges rising in the north, the mid-west and the south. These are the areas that receive the highest rainfall $(200-400 \mathrm{~mm}$ per year) (Morales Matos and Hernandez Torres 1999). The Fuerteventura Stonechat is widely 
distributed from mountains to the coast, mainly on steep, stony and sparsely vegetated ground, being frequent on both open hillsides and in ravines (Bibby and Hill 1987). These findings were supported by a recent study showing that Fuerteventura Stonechats prefer slopes with a high presence of shrubs $(50 \%$ at least) and that they do not occur in lava and sandy fields (Illera 2001).

The status of the Fuerteventura Stonechat was first assessed in 1985 (Bibby and Hill 1987). These authors gave the first scientifically-derived island-wide population estimate of $650-850$ pairs (i.e. 1,300-1,700 birds). Based on this estimate, Saxicola dacotiae was considered a species of European Conservation Concern (SPEC, Category 2), being classified in Europe and Spain as 'Vulnerable' (Tucker and Heath 1994) but currently elevated to 'Endangered' (BirdLife International 2004a,b). It is also included in the Spanish national Red Book as 'Endangered' (Illera 2004, Varela 2007).

In recent years, Distance Sampling methodology has been considered as an efficient and reliable approach to abundance estimation in very different environments (Garcia-del-Rey and Cresswell 2006, Giunchi et al. 2007, Kirkwood et al. 2007). I use this technique and modern GIS to re-evaluate the status of the Fuerteventura Stonechat around twenty years after it was first assessed by Bibby and Hill (1987). At the same time I aim to rank the importance of sites on the island and suggest a conservation strategy based on the findings.

\section{Material and methods}

Fuerteventura is located $96 \mathrm{~km}$ from the Atlantic coast of NW Africa $\left(28^{\circ} 24^{\prime} \mathrm{N}-14^{\circ} \mathrm{O} 6^{\prime} \mathrm{W}\right)$. This volcanic island has a semi-desert climate with dry summers and heavy rain ( $143 \mathrm{~mm}$ annually) in winter (Marzol-Jaén, 1984). The vegetation consists of xerophytic scrub, dominated by a handful of plant species: Launaea arborescens, Euphorbia regis-jubae, Lycium intricatum, Salsola vermiculata, Suaeda spp. and Nicotiana glauca.

\section{Survey design}

Fieldwork was conducted between mid-February and mid-March 2008 to coincide with the peak of reproduction for this species (Illera and Diaz 2006). This timing exploits the greater detectability of Fuerteventura Stonechats, when birds are tied to territories and parents search intensively for insects to feed their chicks.

The present range of the Fuerteventura Stonechat is not precisely known but a first approach, based on map-derived measurements of topography of the whole island, was predicted in 1985 (Bibby and Hill 1987). By means of field visits, the use of orthophoto maps in GIS (Arcview 3.2) and the official vegetation maps (Del Arco et al. 2006), I attempted to predict a new potential distributional range for this species (Figure 1a), as a second approach to further delimit its distributional range. Hence, this new distributional range should not be considered as final and should be readjusted based on future findings. The criteria I used follow the information in the literature (Bibby and Hill 1987, Illera 2001, Snow and Perrins 1998) and my personal observations in the field since 1996. Identifying the different gullies and defining their total area available for the stonechats on Fuerteventura was a straightforward task using GIS, but defining the limits of a hillside is more problematic, especially based on the information available in the literature. Indeed, if the altitudinal belt (and its total area) used to define a hillside is too broad, the final population size for the island will be overestimated (or underestimated if it is too narrow). Bibby and Hill (1987) suggested that stonechats are mainly distributed on 'steep slopes' (mean angle of slope of $24.5^{\circ}$ ) but no altitudinal belt was given. They also pointed out that stonechats do not occur in all apparently suitable locations (i.e. steep stony habitats with reduced vegetation). A more recent study suggested that stonechats select areas with at least $50 \%$ of shrub cover vegetation (Illera 2001). 
a

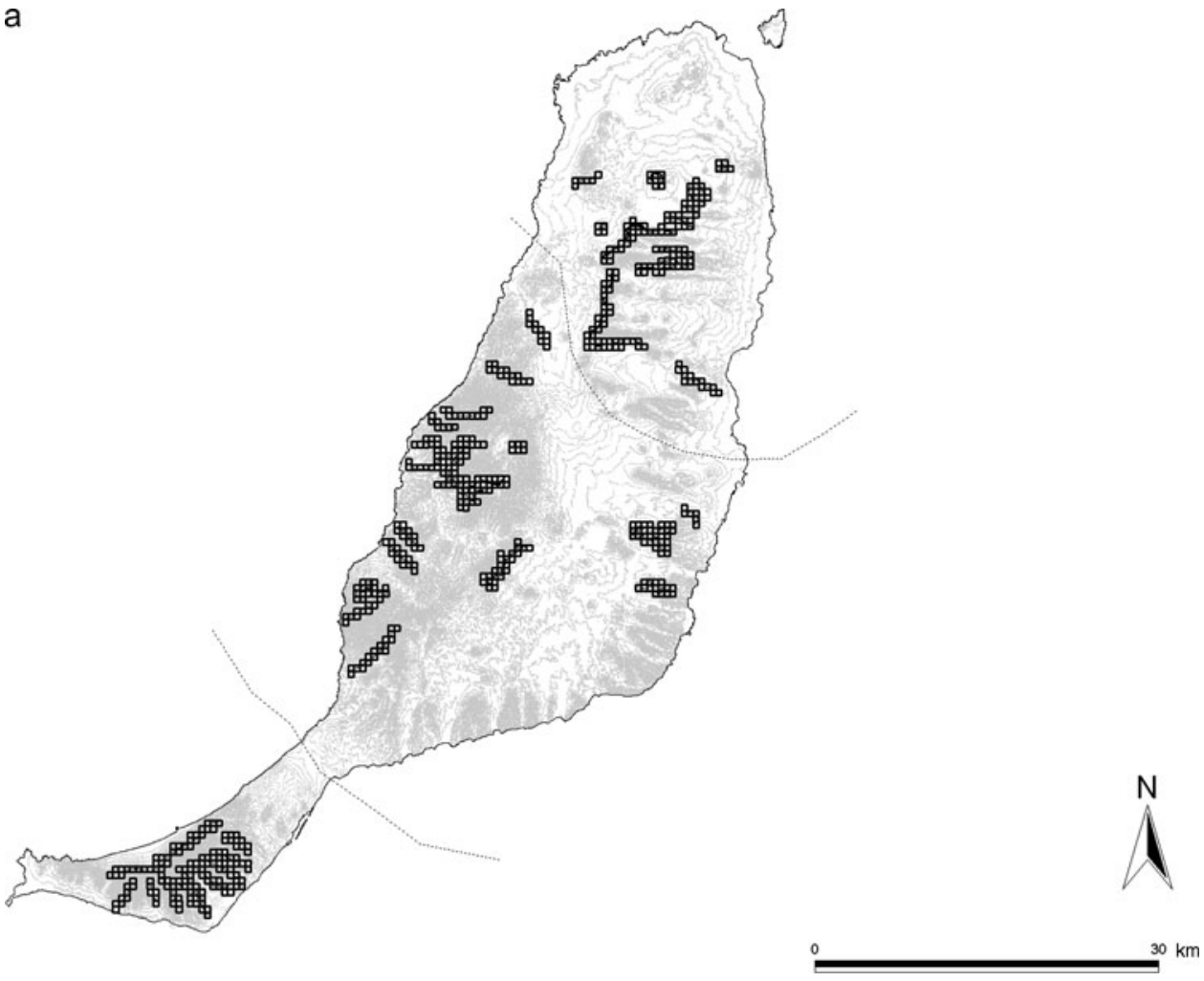

Figure 1a. Distribution of the total $500 \times 500 \mathrm{~m}$ plots estimating the actual distribution of the Fuerteventura Stonechat Saxicola dacotiae.

In an attempt to minimise this problem, I defined the following criteria:

1) For a slope to be considered steep, the lower limit of the altitudinal belt was set at $200 \mathrm{~m}$ a.s.l. The upper limit was the mountain top.

2) I did not exclude any potential hillsides with low shrub cover $(<50 \%)$, being aware that this will overestimate the total population size.

3) I did not use a three dimensional scale map in the GIS, being aware that this will underestimate the real population size for Fuerteventura.

4) Crests were not surveyed in this study and therefore their total occupied area is not included in the final evaluation of the total population size for the island. Apparently, they seem not to be suitable for this species (pers. obs.) and their importance for the stonechats has not been stressed in the past (Bibby and Hill 1987, Illera 2001).

Therefore, surveying was targeted at two habitat strata - gullies and hillsides, which represent the best, and probably only, habitat available for the stonechats on Fuerteventura (Bibby and Hill 1987, Illera 2001, Snow and Perrins 1998). Figure 1 b shows the distribution of plots sampled on the two Fuerteventura Stonechat survey strata. The total area of gullies was estimated at 926 ha $\left(9.26 \mathrm{~km}^{2}\right)$, and that of hillsides at 1,027 ha (total potential area estimated at 1,953 ha). Any finetuning of the area estimated on this study will, clearly, shift the total population size up or down.

Using a regular $500 \times 500 \mathrm{~m}$ grid pattern overlaid on the entire island, 140 plots were selected at random (70 on hillsides and 70 in gullies). Transects were placed at random in the stratum within the grid and sampling was distributed evenly between the two sampling strata and across the entire 


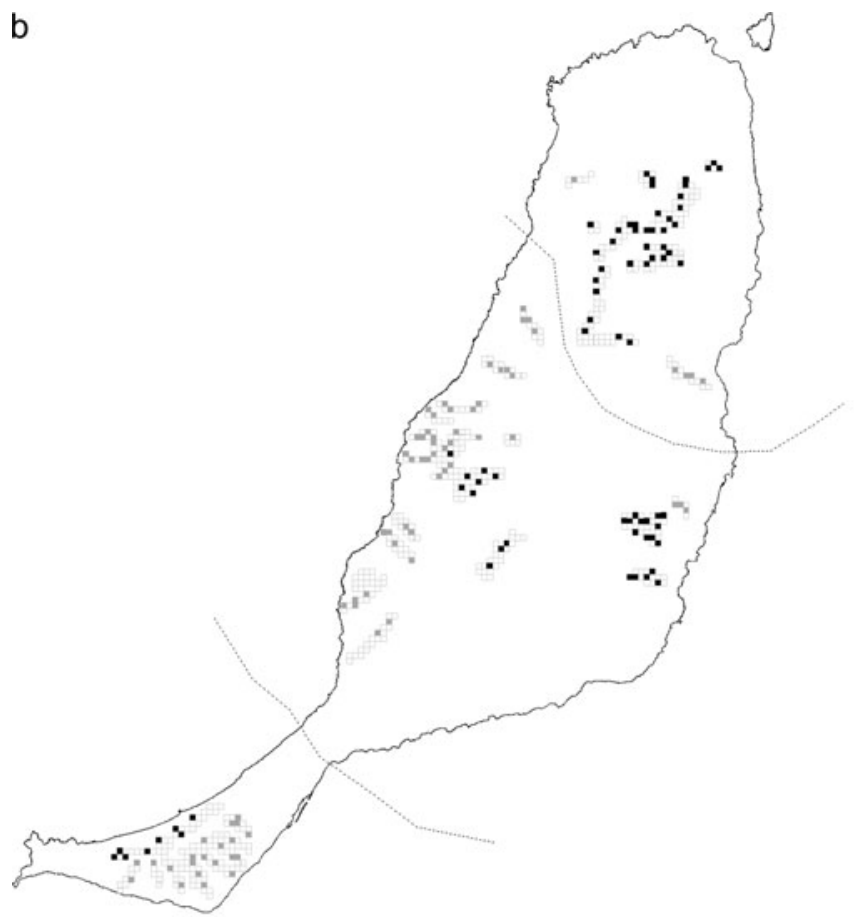

Figure $\mathrm{Ib}$. Distribution of the total $500 \times 500 \mathrm{~m}$ random plots sampled on the two different strata (gully and hillside) on the island of Fuerteventura.

area of the island throughout the survey period. This was done to avoid any bias arising through particular areas or strata being surveyed earlier or later during the reproductive period of the stonechats.

\section{Field methods}

Line transects were surveyed between mid February and mid March 2008, although not in adverse weather conditions (e.g. heavy rainfall, wind over Beaufort scale 4) and only between sunrise and midday. A single observer, the author, walked along the transects, following a GPS bearing, at a pace of $1.0 \mathrm{~km} \mathrm{~h}^{-1}$, halting and scanning with $10 \times 32$ binoculars for approximately 5 seconds at $25 \mathrm{~m}$ intervals, as this increased the chances of stonechat detection, according to the foraging strategy described in Illera (2001). A GPS was used to confirm position at the beginning, centre and end of each 1oom transect, enabling the next sampling unit to be started from the correct location. When a Fuerteventura Stonechat was detected, it was sexed, counted and mapped within sampling unit. The distance of the bird to the observer was measured with the aid of a laser rangefinder ( $\pm 1 \mathrm{~m}$ error), and the bearing was measured by compass, allowing calculation of the perpendicular distance of the point of the bird from the observer using trigonometry.

\section{Population estimates}

The computer software DISTANCE 4.I (Thomas et al. 2004) was used to calculate the effective strip width (ESW), for each stratum, of the transect from the distribution of Fuerteventura Stonechat detections as a function of distance from the transect line. Buckland et al. (2001) 
suggest that a minimum of $60-80$ observations are required in order for DISTANCE to model detection functions successfully and hence produce reliable density estimates. This survey recorded 190 detections ( 120 on hillsides and 70 in gullies). I believe that my survey data fulfilled the assumptions required to be met for validity of DISTANCE sampling analysis (Buckland et al. 2001): (I) the detection of birds was certain along the transect line (a reasonable assumption in such open habitat); (2) recording of distance from transect was highly accurate (a rangefinder was used); (3) bird detections were independent events.

Combinations of all the key models and adjustments were tested in order to find the bestfitting model, i.e. the model with the lowest Akaike's Information Criterion (AIC) (Buckland et al. 2001). Density estimates and abundance were obtained using the program (assuming a Poisson distribution of the variance of the number of observed birds), both at the stratum level and globally, where the global density estimate was the average of the stratum estimates weighted by the stratum area. Buckland et al. (2001) recommend truncating data for DISTANCE analysis by removing $5-10 \%$ of the largest perpendicular distances. In this case, there was only one obvious outlier, at $89 \mathrm{~m}$ from the transect, so this was removed from the data prior to analysis. The truncation distance used was, in effect, $60 \mathrm{~m}$.

\section{Results}

In total, $60.4 \mathrm{~km}$ of transects were surveyed, $30.8 \mathrm{~km}$ were in the hillside stratum and $29.6 \mathrm{~km}$ in the gully stratum. Coverage was spread as evenly as possible over the month of study. During the course of the survey, 190 Fuerteventura Stonechats were recorded by sight (120 on hillsides and 70 in gullies). Virtually even numbers of males and females were recorded: 98 males and 92 females ( 9 fledglings/juveniles were not entered in the analysis).

Stratifying by mountain range (i.e. north, central, south), the highest encounter rate was found in the north; 4.4 contacts $\mathrm{km}^{-1}$ (95\% CI 3.73-5.22) (\% CV 8.58), when compared to the central massif with $1.92 \mathrm{~km}^{-1}$ (95\% CI 1.52-2.43) (\% CV 11.95) and to the southern massif with 1.82 $\mathrm{km}^{-1}$ (95\% CI $\left.0.72-4.58\right)$ (\% CV 50.0). No density estimates were possible in the mountain ranges of the west because the low number of contacts was less than the minimum of $60-80$ recommended by Buckland et al. (2001).

\section{Population estimates}

Of the various model types fitted to the entire data set, the best fit was given by a half-normal/ cosine key function, assuming a Poisson distribution, which gave an effective strip width of $27.6 \mathrm{~m}$ (95\% CI 24.2-31.5) for hillsides and 35.3 m (95\% CI 22.5-55.5) for gullies. The distribution of perpendicular distances, by stratum, of observed Fuerteventura Stonechats can be seen in Figure 2. The optimum model was used to estimate densities in both the strata and globally (Table 1 ), and then extrapolated (assuming a Poisson distribution of the variance of the number of observed birds) to derive an island population estimate of 1,035 (95\% CI 832-1287): 724 (95\% CI 580-906) in the hillside stratum area and 310 (95\% CI 187-516) in the gully stratum. As stated in the methods section, there are still some weaknesses in defining a final potential distributional area for this species. If a simple extrapolation is done from the overall density presented in this study, assuming a 'uniform' distribution within the potential area suggested by Bibby and Hill (1987), the total population estimate will increase dramatically i.e. 0.53 birds (the global density estimate) $\mathrm{x}$ 16,050 ha $=8,506$ birds). However, Bibby and Hill (1987) stated that their total potential area may be overestimated, particularly in the western mountains (inadequately explored by chance).

The potential area in the present study has been corrected by:

1) Not including the area covered by mountain tops (i.e. crests).

2) Limiting the altitudinal belt to one that best represented steepness (i.e. $250-350 \mathrm{~m}$ a.s.l.) in hillsides, where all birds were observed within this stratum. 

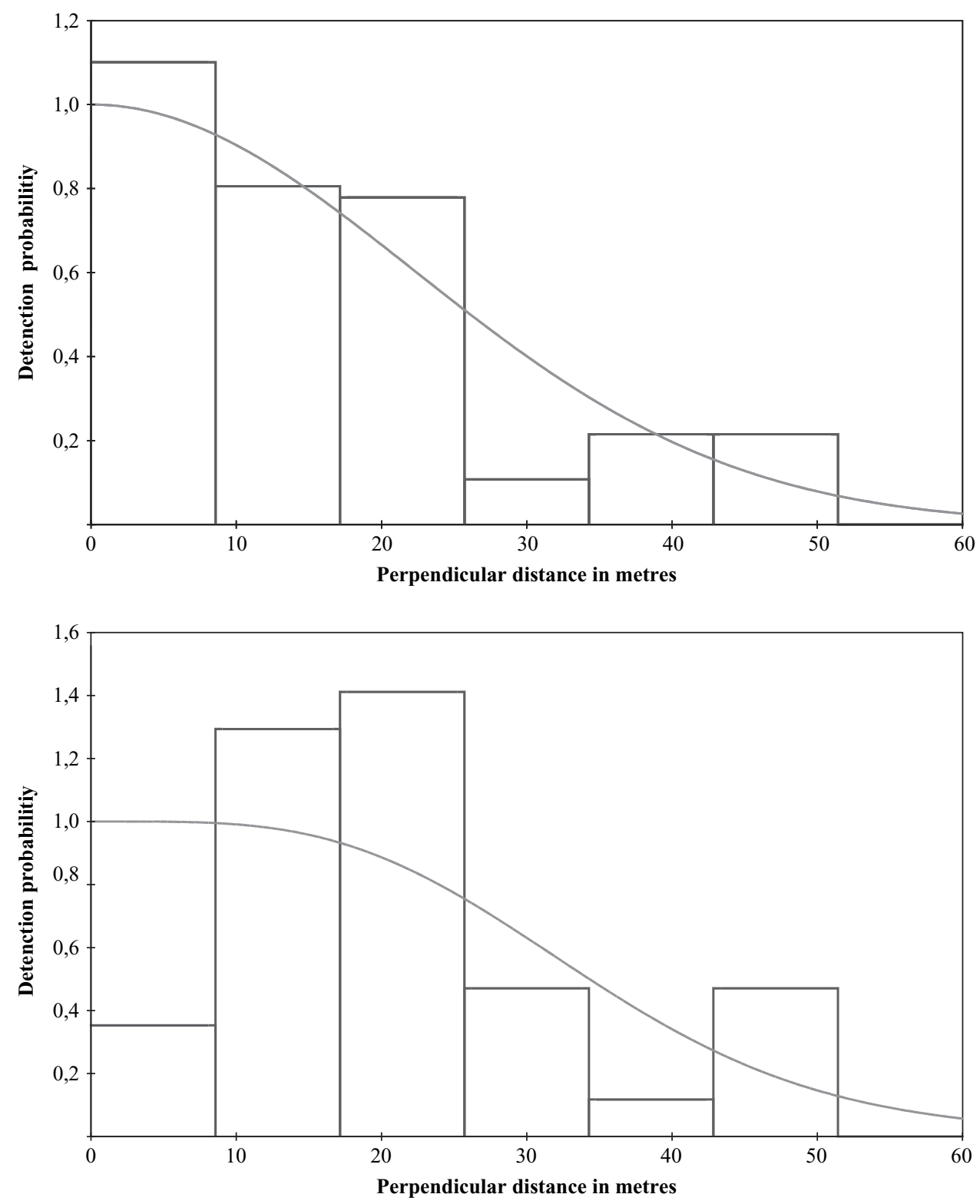

Figure 2. The distribution of perpendicular distances of observed Fuerteventura stonechat Saxicola dacotiae from transect lines in 2008 and the fitted global detection curve for the hillside stratum (above) and the gully stratum (below).

\section{Discussion}

Both Bibby and Hill (1987) and the present study have not been able to provide a final distributional area for the stonechat on Fuerteventura. Despite the different approaches employed (random block on the full island vs random transects in the habitat used by the species) population estimates from the two studies are quite similar. 
Table 1. Fuerteventura Stonechat Saxicola dacotiae island-wide population estimates: global and by stratum. Note that global density estimate is the mean of stratum estimates weighted by stratum total area.

\begin{tabular}{llllll}
\hline Detection & $\begin{array}{l}\text { Total area } \\
\text { (ha) }\end{array}$ & $\begin{array}{l}\text { Density } \\
\left(\text { birds ha }{ }^{-1}\right)\end{array}$ & $(95 \% \mathrm{CI})$ & $\begin{array}{l}\text { Abundance } \\
\text { (individuals) }\end{array}$ & $(95 \% \mathrm{CL})$ \\
\hline Global & 1,953 & 0.53 & $(0.43-0.66)$ & 1,035 & $(832-1,287)$ \\
Hillside & 1,027 & 0.71 & $(0.56-0.88)$ & 724 & $(580-906)$ \\
Gully & 926 & 0.36 & $(0.20-0.56)$ & 310 & $(187-516)$ \\
\hline
\end{tabular}

The results of the present study suggest that the Fuerteventura Stonechat has a population of 1,035 birds (95\% CI 832-1,287), a lower estimate than that given by Bibby and Hill (1987). However, differences in methodology mean that the two estimates are not directly comparable. The first estimate was based on the assumption that all the stonechats in the area were detected. The stonechat is a conspicuous bird on this semiarid island and I agree with the authors' suggestion that not more than $10-20 \%$ of the individuals within an area would have been overlooked (i.e. a $90 \%$ efficient survey). Therefore, this study cannot suggest, that the Fuerteventura Stonechat total population size has decreased since 1985 , but still supports the IUCN classification of 'Endangered'.

Hillsides, particularly in the north, supported higher number of birds when compared to gullies (724 vs 310). On Fuerteventura, very few gullies retain water year round and the sparse shrub vegetation layer is mainly concentrated at the edges. This explains why few birds were detected close to the observer in this stratum (see Figure 2). The distribution of the Fuerteventura Stonechat seems to be closely linked to those areas (i.e. mountain ranges) that receive $200-400 \mathrm{~mm}$ of rainfall per annum (Morales Matos and Hernandez Torres 1999). This also explains the current distribution of other insectivorous passerines such as the Canary Islands Blue Tit Cyanistes teneriffae degener (Garcia-del-Rey 2003, Garcia-del-Rey and Cresswell 2006, Garciadel-Rey et al. 2006), currently on the 'Endangered' list of the Canarian Government. Rainfall might be triggering shrub primary production and therefore the appearance of phytophagous insects. It has been suggested that reproduction of the stonechats on Fuerteventura is closely linked with these insects which are fed to the chicks (Illera and Diaz 2006).

\section{Conservation implications}

All three main mountain ranges on Fuerteventura are protected (Martín-Esquivel et al. 1995) and the main areas for the Fuerteventura Stonechat are included as Important Bird Areas (IBA codes: $339,344,346$; Heath and Evans 2000). Fuerteventura is today under threat from 'uncontrolled' development (Fernadez-Palacios and Martin-Esquivel 2001) and the pressure is highest in the south of the island as new tourist complexes are built every year. The results of the present study suggest that hillsides are particularly important for the Fuerteventura Stonechat in the north. The Fuertevenetura Stonechat has not as yet been categorised as 'Endangered' by the Canarian Government (even though it is considered as such nationally and in Europe) and is not currently subject to any type of monitoring (i.e. no SEGA [Seguimiento de Aves] monitoring programme has been established). I therefore recommend the following:

1) Efforts should be undertaken to improve the knowledge of the distributional area of this species. Either by modelling based on potential area defined in Bibby and Hill (1987), or by systematic visits to the plots presented in this study (adding more or removing if necessary).

2) An intensive survey should be undertaken in the southern massif, as this is the area with the highest risk of losing habitat through development.

3) A monitoring programme should be developed and implemented officially by the Canarian government if this passerine meets the requirements to be considered as Endangered by the local authorities. 


\section{Acknowledgements}

This study received full financial support by the Sociedad Ornitológica Canaria (SOC). I would like to thank Dr Martin Jones and Dr Juan Carlos Illera for constructive comments to improve the manuscript.

\section{References}

Bannerman, D. (1913) Descriptions of Saxicola dacotiae murielae and Acanthis cannabina harterti subsp. n. from Canary Islands. Bull. Brit. Orn. Club 33: 37-39.

Bibby, C. J. and Hill, D. A. (1987) Status of the Fuerteventura Stonechat Saxicola dacotiae. Ibis 129: 491-498.

BirdLife International (2004a) Birds in Europe: Population estimates, trends and conservation status. Cambridge, UK: BirdLife International.

BirdLife International (2004b) Birds in the European Union: a status assessment. Wageningen, The Netherlands: BirdLife International.

Buckland, S. T., Anderson, D. R., Burnham, K. P., Laake, J. L., Borchers, D. L. and Thomas, L. (2001) Introduction to distance sampling: estimating abundance of biological populations. New York: Oxford University Press.

Del Arco, M. J., Wildpret, W., Perez de Paz, P. L., Rodriguez, J. R., Acebes, J. R. Garcia, A., Martin, V. E., Reyes, A., Salas, M., Diaz, M. A., Bermejo, J. A., Gonzalez, R., Cabrera, M. V. and Garcia, S. (2006) Mapa de vegetación de Canarias. Santa Cruz de Tenerife: GRAFCAN.

Fernandez-Palacios, J. M. and Martin-Esquivel, J. L. (2001) Naturaleza de las Islas Canarias. Santa Cruz de Tenerife: Publicaciones Turquesa.

Garcia-del-Rey, E. (2001) Checklist of the birds of the Canary Islands. Santa Cruz de Tenerife: Publicaciones Turquesa.

Garcia-del-Rey, E. (2003) Comparative ecology of the Canary Island Blue Tit complex (Parus caeruleus teneriffae, P.c. palmensis, P.c. ombriosus, P.c. degener). DPhil thesis. University of Oxford.

Garcia-del-Rey, E. and Cresswell, W. (2006) Population size and habitat selection by the Fuerteventura Blue Tit (Parus caeruleus degener) (Canary Islands). Ostrich 77:105-107

Garcia-del-Rey, E., Cresswell, W., Perrins, C. M. and Gosler, A. G. (2006) Variable effects of laying date on clutch size in the Canary Island blue tits (Cyanistes teneriffae). Ibis 148: 564-567.

Giunchi, D., Gaggini, V. and Blaldaccini, N. E. (2007) Distance sampling as an effective method for monitoring feral pigeon $(\mathrm{Co}-$ lumba livia f. domestica) urban populations. Urban Ecosystems 10: 397-412.

Heath, M. F. and Evans, M. I. (200o) Important Bird Areas in Europe: priority sites for conservation. 2 vols. Cambridge, UK: BirdLife International (BirdLife Conservation Series No. 8).

Illera, J. C. (2001) Habitat selection by the Canary Islands Stonechat (Saxicola dacotiae) (Meade-Waldo, 1889) in Fuerteventura island: A two-tier habitat approach with implications for its conservation. Biol. Conserv. 97: 339-345.

Illera, J. C. (2004) Tarabilla Canaria Saxicola dacotiae. Pp. $327-328$ in A. Madroño, C. González and J. C. Atienza, eds. Libro Rojo de las aves de España. Madrid: Dirección General de Biodiversidad-Sociedad Española de Ornitología.

Illera, J. C. and Diaz, M. (2006) Reproduction in an endemic bird of a semiarid island: a food-mediated process. J. Avian Biol. 37: 447-456.

Izquierdo, E., Martín, J. L., Zurita, N. and Arechavaleta, M. (2004) Lista de especies silvestres de Canarias (hongos, plantas y animales terrestres) 2004. Santa Cruz de Tenerife: Gobierno de Canarias.

Kirkwood, R. K., Lawton, J. and Moreno, C. (2007). Estimates of southern rockhopper and macaroni penguin numbers at the Ildefonso and Diego Ramirez archipelagos, Chile, using quadrat and distance-sampling techniques. Waterbirds 30: 259-267.

Martín-Esquivel, J. L., García, H., Redondo, C. E., García, I. and Carralero, I. (1995) La 
red canaria de espacios naturales protegidos. Santa Cruz de Tenerife: Gobierno de Canarias.

Marzol-Jaén, M. V. (1984) El clima. Pp. 179200 in J. Afonso, ed. Geografía de Canarias. Santa Cruz de Tenerife: Interinsular Canaria.

Meade-Waldo, E. G. B. (1889) Notes on some birds on the Canary Islands. Ibis 6: 1-13.

Morales Matos, G. and Hernandez Torres, S. (1999) La geografía de Canarias. Pp. 24-58 in C. Rodríguez Placeres and R. Sosa Díaz, eds. La enciclopedia temática e ilustrada de Canarias. Santa Cruz de Tenerife: Centro de Cultura Popular Canaria.

Snow, D. W. and Perrins, C. M. (1998) The birds of the western Palearctic. Concise edition. Volume 2. New York: Oxford University Press.

Stattersfield, A. J., Crosby, M. J., Long, A. J. and Wege, D. C. (1998) Endemic bird areas of the world. Cambridge, UK: BirdLife International.
Thomas, L., Laake, J. L., Strindberg, S., Marques, F. F. C., Buckland, S. T., Borchers, D. L., Anderson, D. R., Burnham, K. P., Hedley, S. L., Pollard, J. H. and Bishop, J. R. B. (2004) Distance 4.1. Release 1. Research unit for wildlife population assessment, University of St. Andrews, UK. Url:http:// www.Ruwpa.St-and.Ac.Uk/distance/

Tucker, G. and Heath, M. F. (1994) Birds in Europe: their conservation status. Cambridge, UK: BirdLife International. (BirdLife Conservation Series $\mathrm{n}^{\circ}$ ).

Tucker, G. M., and Evans, M. I. (1997). Habitats for birds in Europe. A conservation strategy for the wider environment. Cambridge, UK: BirdLife International.

Varela, J. M. (2007). Aves amenazadas de España. Barcelona: Lynx Edicions.

Wink, M., Sauer-Guerth, H. and Gwinner, E. (2002) Evolutionary relationships of stonechats and related species inferred from mtDNA sequences and genomic fingerprinting. British Birds 95: 349-355.

\section{EDUARDO GARCIA-DEL-REY}

Departamento de Ecología, Facultad de Biología, Universidad de La Laguna, 38206 La Laguna, Tenerife, Canary Islands, Spain.e-mail:edugdr@ull.es 